\title{
Lamotrigine-Related Severe Cutaneous Adverse Reaction in Patient with Epilepsy
}

\section{${ }^{1} \mathrm{Al}-$ Quliti $\mathrm{KW}^{*}$ and Al-Amri $\mathbf{M S}^{2}$}

${ }^{1}$ Department of Medicine, College of Medicine, Taibah University, Saudi Arabia

${ }^{2}$ Department of Nursing, College of Applied Medical Sciences, Majmaah University, Saudi Arabia

\begin{abstract}
Background: Epilepsy is a common neurological disorder for which lamotrigine is an effective antiepileptic medication as monotherapy or as an add-on therapy with good tolerability and safety profile. Side effects, including serious skin reactions, can develop during treatment with lamotrigine and can be life threatening. The aim of this research is to study the local experience of adult Saudi patients with epilepsy who developed lamotrigine-related skin reactions.

Methods: This observational retrospective study included all epilepsy patients who received lamotrigine and were followed up in the adult epilepsy clinic at King Fahad Hospital, Madinah, Saudi Arabia, between July 2011 and June 2014.

Results: A total of 147 epilepsy patients received lamotrigine. Eleven patients $(7.48 \%)$, aged 24 to 62 years old (mean 39.73 SD 11), of which 6 were male (54.5\%) and 5 female (45.5\%), developed cutaneous adverse drug reactions. Lamotrigine was used as monotherapy in one patient and as add-on therapy for 10 patients. Eight patients $(72.73 \%)$ had high liver enzymes. Seven patients $(63.6 \%)$ had systemic symptoms. Cutaneous adverse drug reactions were noted 1 to 4 weeks after lamotrigine initiation (mean $=2.36$, mode $=3$ ); 7 patients $(63.63 \%)$ had maculopapular rashes, and 4 patients $(36.37 \%)$ had urticaria. Six patients $(54.5 \%)$ had good recovery; 1 patient developed sepsis; 2 patients developed hyperpigmentations; and 2 patients developed drug reactions with eosinophilia and systemic symptoms.
\end{abstract}

Conclusion: Lamotrigine is an effective medication for management of epilepsy and other nervous system disorders, with a good tolerability and safety profile. However, lamotrigine-related cutaneous adverse drug reactions can be serious and healthcare providers' thorough clinical knowledge of the potential side effects of lamotrigine is crucial in clinical practice particularly when patients receive multiple antiepileptic drugs.

Keywords: Epilepsy; Lamotrigine; Skin rash; DRESS syndrome

\section{Background}

Epilepsy is a tendency to recurrent, spontaneous, and unprovoked seizures arising from excessive, synchronous, abnormal, discharge of neurons in the cerebral cortex [1]. It affects more than 65 million people worldwide, with an annual incidence of 50/100,000 people [1]. Nearly $1 \%$ of the population suffers from epilepsy worldwide [2]. The causes of epilepsy include head injury, alcohol abuse, stroke, and brain tumors [1]. Morbidity due to epilepsy can be correlated to the effects of seizures and/or treatment [3].

Antiepileptic drugs (AED) are the treatment of choice for management of patients with epilepsy [3]. Approximately $60-70 \%$ of patients with epilepsy may have controlled seizures with proper medical treatments [3]. However, these medications may have side effects which can be life-threatening, thus clinical knowledge of potential side effects of AEDs is crucial to overcome treatment failure and possible adverse reactions [4]. Drug rash is a recognized side effect of some AEDs and severe forms of cutaneous reactions can occur $[5,6]$.

Lamotrigine (LTG) is an aromatic phenyltriazine class antiepileptic drug, with two benzene rings, displaying linear pharmacokinetics. It works through stabilizing synaptic membrane and glutamate release and calcium channel control by blocking the voltage-dependent sodium channel, and inhibiting the release of excitatory neurotransmitters such as glutamate and aspartate [7-9]. It has good absorption level with relatively fewer drug interactions [9].

Lamotrigine, approved by the U.S. Food and Drug Administration (FDA) in 1994, has been used in the U.S. for the last 2 decades as adjunctive therapy to treat partial and generalized seizures in adult patients, and since 1998 as a monotherapy [10]. Additionally, LTG was also used to treat bipolar I disorder and as adjunctive therapy for the management of seizures associated with Lennox-Gastaut syndrome [9-11]

LTG is a well-tolerated AED with possible side effects such as: headache, dizziness, nausea, somnolence, rhinitis, blurred vision, diplopia, ataxia, constipation, and dry mouth [9]. Furthermore, LTG has rare adverse severe skin reactions such as: Stevens-Johnson syndrome (SJS), toxic epidermal necrolysis (TEN), drug rash with eosinophilia and systemic symptoms (DRESS), and anticonvulsant hypersensitivity syndrome, which may lead to terminating LTG treatment [9-11]. Slow introduction and titration of LTG dosage may reduce or eliminate these adverse symptoms [9].

In the case of AED-related cutaneous adverse drug reactions (CADR); healthcare providers should take an accurate medical history and document all medications used by the patient, especially recently introduced medication. A detailed description of the skin rash and its characteristics is essential $[12,13]$. Early pattern recognition and appropriate assessment of these reactions play a major role in initial management of such skin reactions, and may prevent further

*Corresponding author: Khalid W Al-Quliti, Taibah University, Almadinah Almunawwarah, Saudi Arabia, Tel: 00966582425777; E-mail: kh_alquliti@yahoo.com

Received October 05, 2015; Accepted October 26, 2015; Published October 29 2015

Citation: Al-Quliti KW, Al-Amri MS (2015) Lamotrigine-Related Severe Cutaneous Adverse Reaction in Patient with Epilepsy. J Neurol Disord S1: 005. doi:10.4172/2329-6895.S1-005

Copyright: ( 2015 Al-Quliti KW. This is an open-access article distributed under the terms of the Creative Commons Attribution License, which permits unrestricted use, distribution, and reproduction in any medium, provided the original author and source are credited. 
complication [9]. However, determination of the exact etiology is more difficult when multiple AEDs are being used.

The aim of this study is to document our local experience of LTGinduced CADR in adult patients with epilepsy in Madinah region, Saudi Arabia. This region has a population of 2 million people. To date, there is no article in the literature addressing this issue. Thus, this study may add to the database of knowledge and local experience related to treatment of patients with epilepsy in Saudi Arabia, and compare it to international data that may improve the standard of patient care.

\section{Method}

This is an observational retrospective study. The researchers included all patients who met the inclusion criteria: adult patients between 18 and 70 years old who use LTG as monotherapy or addon therapy. Exclusion criteria were: patients with a history of chronic severe skin disease, bone marrow transplant and vasculitis.

All patients were from the adult epilepsy clinic in the neurology service at King Fahad Hospital Madinah, between July 2011 and June 2014. This is the only public adult neurology service in the Madinah region and covers the major public hospitals (King Fahad Hospital, Ohod Hospital, and Alansar Hospital), as well as referrals from all primary healthcare centers in the region. These patients were followed up by a certified adult epileptologist Patients were educated about the risk/benefit ratio and possible side effects of AEDs. LTG was initiated with a standard dose of $25 \mathrm{mg}$ once daily for 2 weeks; then increased to $25 \mathrm{mg}$ twice a day for the next 2 weeks. Then from week 5 onwards the dose was increased by $25-50 \mathrm{mg}$ every 1 to 2 weeks to a maintenance dose of 50-100 mg twice a day. Patients who stated LTG as an add-on therapy, who were also prescribed valproic acid (VPA), were given an initial LTG dose of $25 \mathrm{mg}$ every other day for the first 2 weeks. During weeks 3 and 4, a dose of $25 \mathrm{mg}$ once a day was prescribed; then increased by $25 \mathrm{mg}$ every 1 to 2 weeks to a maintenance dose of $50 \mathrm{mg}$ twice a day. This was due to the fact VPA doubles the elimination half-life of LTG and reduces plasma clearance by 50\% [9]. Patients on other AEDs that induce LTG glucuronidation such as carbamazepine (CBZ), phenytoin (PHT), and phenobarbital were treated with adjusted LTG doses of 50

\begin{tabular}{|l|c|c|c|c|c|c|c|}
\hline & Age & Gender & $\begin{array}{c}\text { Classification } \\
\text { of epilepsy }\end{array}$ & $\begin{array}{c}\text { Current } \\
\text { other } \\
\text { AEDs }\end{array}$ & $\begin{array}{c}\text { Previous } \\
\text { AEDs }\end{array}$ & $\begin{array}{c}\text { Duration } \\
\text { of epilepsy } \\
\text { years }\end{array}$ & $\begin{array}{c}\text { Co } \\
\text { morbidity }\end{array}$ \\
\hline 1 & 28 & M & Generalized & VPA & - & 4 & None \\
\hline 2 & 39 & M & PSGE & CBZ & + & 7 & $\begin{array}{c}\text { Bronchial } \\
\text { asthma }\end{array}$ \\
\hline 3 & 49 & F & PSGE & CBZ & + & 14 & None \\
\hline 4 & 62 & F & PSGE & PHT & - & 2 & $\begin{array}{r}\text { HTN } \\
+ \text { stroke }\end{array}$ \\
\hline 5 & 24 & F & Generalized & PHT & - & 11 & eczema \\
\hline 6 & 32 & M & Unclassified & VPA & + & 17 & None \\
\hline 7 & 41 & M & PSGE & - & + & 12 & None \\
\hline 8 & 38 & M & PSGE & PHT & - & 6 & NPM \\
\hline 9 & 31 & F & Generalized & VPA & + & 2 & None \\
\hline 10 & 44 & M & PSGE & CBZ & + & 6 & None \\
\hline 11 & 49 & F & PSGE & VPA & + & 9 & DM \\
\hline
\end{tabular}

PSGE: Partial Secondary Generalized Epilepsy; VPA: Valproic acid; TPM: Topiramate; CBZ: Carbamazepine; PHT: Phenytoin.

Table 1: Clinical and demographic characteristics of patients treated with LTG. mg once a day for first 2 weeks, then $50 \mathrm{mg}$ twice a day for weeks 3 and 4, which was increased by $50 \mathrm{mg}$ every 2 weeks to a target maintenance dose of 100-150 mg twice a day. Patients were on regular follow-up visits to the epilepsy clinic at 2, 4, and 8 weeks after LTG introduction.

Researchers reviewed the medical files for cutaneous adverse reactions. Data on demographics, medical history, diagnosis and duration of epilepsy and the use of AEDs were collected. Information on drug history, the clinical and temporal pattern of CADR, presence of mucosal rash and associated systemic symptoms including fever, malaise, irritability, nausea, and vomiting were obtained. Biochemical profiles including liver enzymes and eosinophil counts were collected, as well as clinical course and outcome data. Ethical approval for the research was obtained from local authorities.

\section{Result}

A total of 147 patients received LTG; 11 patients (7.48\%) developed CADR (Table 1). Their age ranged from 24 to 62 years old (mean 39.73); the gender of patients with CADR was 6 male patients $(54.5 \%)$ and 5 female patients (45.5\%). Classifications of epilepsy: 7 patients $(63.6 \%)$ had partial secondary generalized epilepsy (PSGE), 3 patients (27.3\%) with generalized epilepsy, and 1 patient (9.1\%) with unclassified epilepsy.

LTG was used as monotherapy in 1 patient and as an add-on therapy in 10 patients of which 4 patients were on VPA, 3 patients were on CBZ, 2 patients were on PHT, and 1 patient was on PHT and topiramate (TPM). Seven patients (63.6\%) had used AEDs previously, while $4(36.4 \%)$ had not used any previous AEDs.

Duration of epilepsy ranged from 2 to 17 years (mean 8.18). One patient was diagnosed with bronchial asthma, 1 with eczema, 1 with diabetes mellitus, and 1 with hypertension and stroke; 7 patients did not have any comorbidity. Three patients with CADR had a previous history of hypersensitivity to other AEDs.

Eight patients with CADR (72.73\%) had high liver enzymes including aspartate transaminases (AST), and alanine aminotransferase (ALT) (Table 2). Seven patients (63.6\%) had systemic symptoms such as fever, malaise, irritability, nausea, and vomiting. The onset of CADR after starting LTG ranged from 1 to 4 weeks (mean $=2.36$, mode $=3$ ). The clinical pattern of CADR showed 7 patients (63.63\%) with maculopapular rash, and 4 patients (36.37\%) had urticaria.

Clinical course documents showed 6 patients (54.5\%) had a good recovery; 1 patient developed sepsis; 2 patients developed hyperpigmentations, and 2 patients developed drug rash with DRESS.

\section{Discussion}

Lamotrigine is an approved AED with a good efficacy and safety profile. However, studies reported $10 \%$ of patients may develop skin rash to LTG which might be severe and life-threatening [10]. The incidence of skin rash with LTG therapy in this study was $7.48 \%$, which is lower than the reported rate, probably because of the low doses and slow titration. The incidence of skin rash with LTG is doseand titration-dependent $[10,14]$. In this study, 6 males and 5 females developed CADR. However, previous studies showed different results on the incidence of CADR in regard to gender, as some report a male preponderance, while others showed a female preponderance [15]. Mokhtari et al. reported that female gender was a risk factor due to different pharmacokinetics and hormonal effects [16].

The findings of this study showed the mean age of patients with CADR ranged from 24 to 62 years old (Mean 39.73, SD 11), which is 
Page 3 of 4

\begin{tabular}{|c|c|c|c|c|c|c|c|c|c|}
\hline & \multirow{2}{*}{ Age } & \multirow{2}{*}{ Gender } & \multicolumn{2}{|c|}{$\begin{array}{c}\text { Liver } \\
\text { Enzymes }\end{array}$} & \multirow{2}{*}{$\begin{array}{c}\text { Systemic } \\
\text { symptoms }\end{array}$} & \multicolumn{2}{|c|}{$\begin{array}{l}\text { Cutaneous } \\
\text { manifestation }\end{array}$} & \multirow{2}{*}{ Hospital course } & \multirow{2}{*}{ Clinical outcome } \\
\hline & & & $\begin{array}{l}\text { ALT } \\
\text { IU/L }\end{array}$ & $\begin{array}{l}\text { AST } \\
\text { IU/L }\end{array}$ & & $\begin{array}{c}\text { Onset } \\
\text { In weeks }\end{array}$ & $\begin{array}{c}\text { Skin } \\
\text { manifestation }\end{array}$ & & \\
\hline 1 & 28 & $M$ & 28 & 34 & - & 1 & $\begin{array}{l}\text { Maculopapular } \\
\text { rash }\end{array}$ & $\begin{array}{c}\text { General } \\
\text { ward (LHS) }\end{array}$ & $\begin{array}{l}\text { Good } \\
\text { recovery }\end{array}$ \\
\hline 2 & 39 & $M$ & 188 & 209 & + & 2 & Urticarial & $\begin{array}{c}\text { Intensive } \\
\text { care unit with MV } \\
(\mathrm{LHS})\end{array}$ & $\begin{array}{l}\text { Good } \\
\text { recovery }\end{array}$ \\
\hline 3 & 49 & $\mathrm{~F}$ & 86 & 71 & + & 4 & $\begin{array}{l}\text { Maculopapular } \\
\text { rash }\end{array}$ & $\begin{array}{c}\text { General } \\
\text { ward } \\
\text { Good recovery }\end{array}$ & $\begin{array}{l}\text { Good } \\
\text { recovery }\end{array}$ \\
\hline 4 & 62 & $\mathrm{~F}$ & 67 & 52 & - & 2 & $\begin{array}{l}\text { Maculopapular } \\
\text { rash }\end{array}$ & $\begin{array}{c}\text { General } \\
\text { ward } \\
\text { Good recovery }\end{array}$ & $\begin{array}{l}\text { Good } \\
\text { recovery }\end{array}$ \\
\hline 5 & 24 & $\mathrm{~F}$ & 201 & 132 & + & 3 & Urticarial & $\begin{array}{l}\text { Intensive } \\
\text { care unit } \\
\text { (LHS) }\end{array}$ & $\begin{array}{c}\text { Hyper- } \\
\text { pigmentations }\end{array}$ \\
\hline 6 & 32 & $M$ & 24 & 47 & + & 3 & $\begin{array}{l}\text { Maculopapular } \\
\text { rash }\end{array}$ & $\begin{array}{c}\text { General } \\
\text { ward (LHS) }\end{array}$ & Sepsis \\
\hline 7 & 41 & $M$ & 63 & 71 & - & 3 & Urticarial & $\begin{array}{l}\text { General } \\
\text { ward }\end{array}$ & $\begin{array}{l}\text { Good } \\
\text { recovery }\end{array}$ \\
\hline 8 & 38 & $M$ & 137 & 182 & + & 1 & $\begin{array}{l}\text { Maculopapular } \\
\text { rash }\end{array}$ & $\begin{array}{l}\text { General } \\
\text { ward } \\
(\mathrm{LHS})\end{array}$ & $\begin{array}{c}\text { Hyper- } \\
\text { pigmentations }\end{array}$ \\
\hline 9 & 31 & $\mathrm{~F}$ & 389 & 242 & + & 3 & $\begin{array}{l}\text { Maculopapular } \\
\text { rash }\end{array}$ & $\begin{array}{l}\text { Intensive } \\
\text { care }\end{array}$ & DRESS \\
\hline 10 & 44 & M & 42 & 31 & - & 4 & Urticarial & $\begin{array}{l}\text { General } \\
\text { ward }\end{array}$ & $\begin{array}{l}\text { Good } \\
\text { recovery }\end{array}$ \\
\hline 11 & 49 & $\mathrm{~F}$ & 276 & 311 & + & 2 & $\begin{array}{l}\text { Maculopapular } \\
\text { rash }\end{array}$ & $\begin{array}{c}\text { Intensive } \\
\text { care unit(LHS) }\end{array}$ & DRESS \\
\hline
\end{tabular}

Aspartate transaminases (AST); alanine aminotransferase (ALT); Mechanical ventilation (MV); longer hospital stay (LHS); Drug rash with eosinophilia and systemic symptoms (DRESS).

Table 2: Clinical profile of hypersensitivity reaction related to LTG.

similar to previous studies [16]. However, Blaszczyk et al. found no significant association between LTG-CADR and age [15]. Moreover, Mokhtari et al. reported a higher frequency of CADR in the younger age group [16]. Huang et al. demonstrated a significantly younger average age $(\mathrm{P}<0,001)$ in patients with severe reactions, compared with non-severe reactions [17].

Our study revealed 4 patients were on VPA and 3 were on CBZ; other studies also showed a similar finding with AEDs add on therapy of LTG, VPA and CBZ. VPA affects the LTG level through inhibiting hepatic glucuronides, which subsequently increases the serum level of LTG in the blood $[7,18,19]$.

One of our patients was diagnosed with bronchial asthma and 3 patients had a previous history of hypersensitivity to other AEDs. Earlier studies reported asthmatic patients are at higher risk of hypersensitivity reactions as well as patients with allergies [19].

Findings in this study indicated 9 patients with CADR (81.8\%) had high liver enzymes. Previous studies reported different spectrum of liver dysfunction from LTG use, from mild liver enzyme elevation to fulminant hepatic failure [8]. Many patients showed improvement after stopping AEDs. Furthermore, combined treatment with VPA and LTG was observed to cause hepatotoxicity through decreased clearance of LTG $[8,11]$.

In our retrospective study, 3 out of 4 patients with polytherapy (VPA and LTG) had complications. One patient with sepsis was treated with intravenous antibiotics, and two patients experienced DRESS, while, a fourth patient had good recovery. In our study, 3 patients on polytherapy (CBZ and LTG) had good recovery. One patient on polytherapy (PHT, TPM, and LTG) developed hyperpigmentations. Yang et al. reported that LTG, CBZ, and phenobarbital were the major AEDs causing severe forms of CADR in Asians [20].

In our study, lamotrigine was discontinued in all patients immediately and symptomatic treatment was initiated. All patients with CADR were hospitalized, 8 patients were admitted to general wards, and 3 were admitted to intensive care units. Seven patients had hospital stays of more than 10 days. Furthermore, previous studies showed CADR could result in hospital admission, prolonged hospital stay, increased morbidity, or even mortality [16].

Findings indicated 7 patients (63.63\%) had maculopapular rash, and 4 patients $(36.37 \%)$ had urticaria. Other studies showed the most frequent clinical patterns of CADR were maculopapular rash, urticria, and erythroderma [21].

DRESS was initially proposed by Bocquet and his colleagues in 1996. They described a serious disease that can result in multi-organ failure and significant morbidity and mortality with idiosyncratic reaction that occurs most commonly after exposure to drugs such as aromatic anticonvulsants, antibiotics and analgesics/anti-inflammatories [6]. The incidence of DRESS is 0.4 cases per $1,000,000$ population [22]. The syndrome is defined by the presence of at least three of the following findings fever, exanthema, eosinophilia, atypical circulating lymphocytes, lymphadenopathy, and hepatitis [23]. 
Citation: Al-Quliti KW, Al-Amri MS (2015) Lamotrigine-Related Severe Cutaneous Adverse Reaction in Patient with Epilepsy. J Neurol Disord S1: 005. doi:10.4172/2329-6895.S1-005

Page 4 of 4

Two of our patients were diagnosed with DRESS (18.185), both were female, aged 31 and 49 years old. Their liver enzymes were more than five-fold normal levels, their eosinophil counts were 2145 109/L and 1924 109/L, respectively. Both had systemic symptoms, both had maculopapular rash, and one of them developed erythema multiforme. Fleming et al. reported clinical manifestations are usually maculopapular [23]; nevertheless, erythrodermia, bullous, and erythematopustular rashes have been reported. Both patients were managed in the ICU with systemic steroids, antihistamine, and antibiotics. Both patients were discharged from the hospital after longer hospital stays than planned. According to earlier studies, early withdrawal of the offending medication improves prognosis and supports the use of steroids in management of DRESS syndrome [24,25].

Limitations of this study included: it was a retrospective study that depends on available data in the medical charts, and it was limited to one region in Saudi Arabia. Further studies that include histopathological data and HLA genotype may add valuable information for management of epilepsy in Saudi Arabia.

In conclusion, LTG is an effective antiepileptic medication for management of epilepsy and other nervous system disorders, with a good tolerability and safety profile. The finding of our study reviled a lower rate of CADRs than reported in other studies probably due to low dose and slower titration. Clinical knowledge of healthcare providers of side effects of LTG and other AEDs is crucial in managing patients on AEDs, as they might develop severe CADRs. Special consideration should be given when starting treatment with LTG and dose titrations, especially in cases of polytherapy with others AEDs, such as VPA.

\section{References}

1. Sinha S, Siddiqui KA (2011) Definition of intractable epilepsy. Neurosciences (Riyadh) 16: 3-9.

2. Hassan A, Al-Quliti KW (2014) Neurostimulation. A promising therapeutic option for medically refractory epilepsy. Neurosciences (Riyadh) 19: 4-10.

3. Moshé SL, Perucca E, Ryvlin P, Tomson T (2015) Epilepsy: new advances. Lancet 385: 884-898.

4. AIQuliti K, Ratrout B, AIZaki A (2014) Antiepileptic drugs toxicity: A case of toxic epidermal necrolysis in patient with phenytoin prophylaxis post-cranial radiation for brain metastases. Saudi Pharm J 22: 381-384.

5. Arif H, Buchsbaum R, Weintraub D, Koyfman S, Salas-Humara C, et al. (2007) Comparison and predictors of rash associated with 15 antiepileptic drugs. Neurology 68: 1701-1709.

6. Turcu G, Nedelcu RI, Forsea D (2012) Drug rash with eosinophilia and systemic symptoms (DRESS) caused by lamotrigine. A case report and brief review. Therapeutics, Pharmacology and Clinical Toxicology 151: 66-69.

7. Jan MM (2007) Potentially serious Lamotrigine-related skin rash. Neurosciences (Riyadh) 12: 17-20.
8. Sung GI, Sun HY, Young MP, Sang JL, Sun KJ, et al. (2015) Liver dysfunction induced by systemic hypersensitivity reaction to lamotrigine: case report. Clinical and Molecular Hepatology 21: 190-192.

9. Lamictal (2015) GlaxoSmithKline Inc. Mississauga, Ontario.

10. Schiller Y, Krivoy N (2009) Safety and efficacy of lamotrigine in older adults with epilepsy and co-morbid depressive symptoms. Clinical Medicine Insights: Therapeutics 1: 825-833.

11. Serwetman L, Krikorian SA, Javedian H (2008) Rash and liver dysfunction related to lamotrigine therapy. J Pharm Tech 24: 17-21.

12. Hirsch LJ, Weintraub DB, Buchsbaum R, Spencer HT, Straka T, et al. (2006) Predictors of Lamotrigine-associated rash. Epilepsia 47: 318-322.

13. Segal AR, Doherty KM, Leggott J, Zlotoff B (2007) Cutaneous reactions to drugs in children. Pediatrics 120: e1082-1096.

14. Wang XQ, Xiong J, Xu WH, Yu SY, Huang XS, et al. (2015) Risk of a lamotrigine-related skin rash: current meta-analysis and postmarketing cohort analysis. Seizure 25: 52-61.

15. BÅ,aszczyk B, Szpringer M, Czuczwar SJ, Laso̊̊ W (2013) Single centre 20 year survey of antiepileptic drug-induced hypersensitivity reactions. Pharmacol Rep 65: 399-409.

16. Mokhtari F, Nikyar Z, Naeini BA, Esfahani AA, Rahmani S (2014) Adverse cutaneous drug reactions: Eight year assessment in hospitalized patients. J Res Med Sci 19: 720-725.

17. Huang HY, Luo XQ, Chan LS, Cao ZH, Sun XF, et al. (2011) Cutaneous adverse drug reactions in a hospital-based Chinese population. Clin Exp Dermatol 36: 135-141.

18. Vajda FJ, Dodd S, Horgan D (2013) Lamotrigine in epilepsy, pregnancy and psychiatry--a drug for all seasons? J Clin Neurosci 20: 13-16.

19. Castro-Pastrana LI, Ghannadan R, Rieder MJ, Dahlke E, Hayden M, et al. (2011) Cutaneous adverse drug reactions in children: an analysis of reports from the Canadian Pharmacogenomics Network for Drug Safety (CPNDS). J Popul Ther Clin Pharmacol 18: e106-120.

20. Yang CY, Dao RL, Lee TJ, Lu CW, Yang CH, et al. (2011) Severe cutaneous adverse reactions to antiepileptic drugs in Asians. Neurology 77: 2025-2033.

21. Rahmati M, Shadnia S, Abdollahi M (2009) Drug-induced skin events in hospitalized patients in Tehran, Iran: a 6-year case series study. Arch Med Sci 1: 91-106.

22. Pereira de Silva N, Piquioni $P$, Kochen S, Saidon P (2011) Risk factors associated with DRESS syndrome produced by aromatic and non-aromatic antipiletic drugs. Eur J Clin Pharmacol 67: 463-470.

23. Fleming P, Marik PE (2011) The DRESS syndrome: the great clinical mimicker. Pharmacotherapy 31: 332.

24. Eshki M, Allanore L, Musette P, Milpied B, Grange A, et al. (2009) Twelve-year analysis of severe cases of drug reaction with eosinophilia and symptoms: a cause of unpredictable multiorgan failure. Arch Dermatol 145: 67-72.

25. Cacoub P, Musette P, Descamps V, Meyer O, Speirs C, et al. (2011) The DRESS syndrome: a literature review. Am J Med 124: 588-597.
This article was originally published in a special issue, Management of Neurosurgical Complications handled by Editor(s). Dr. Athanasios K. Petridis, Department of Neurosurgery, University of Schleswig Holstein, Germany 